\title{
CONSIDERAÇÕES SOBRE A FORMAÇÃO DO PSICÓLOGO NO BRASIL: REVISÃO SISTEMÁTICA
}

\author{
Bianca Veiga Prates \\ Universidade Federal da Bahia
}

Ellen Araújo Lima Feitosa

Universidade Federal da Bahia

Paulo Souza Monteiro

Universidade Federal da Bahia

Paulo Coelho Castelo Branco

Universidade Federal da Bahia

\begin{abstract}
Resumo
Objetivamos analisar o estado corrente de produções sobre a formação do psicólogo nas bases SciELO e PePSIC, segundo uma revisão sistemática de 118 artigos, categorizados conforme ano, periódico, autoria, filiação, região, tipo de pesquisa, método e tema. Os resultados demonstram: aumento de produções nesta década; concentração de publicações na revista Psicologia: Ciência e Profissão; ampla variedade de autores e filiações, com proeminência de produções no sudeste; preponderância de metodologias empíricas que usam análise documental; prevalência de temáticas relacionadas à formação acadêmico-científica. Indicamos que existe uma dispersão sobre o que seria formação do psicólogo. Há muitos estudiosos que fazem incursões pontuais sobre o tema. Necessita-se de mais discussões sobre a formação nos interiores brasileiros, que atualmente concentram a maioria de alunos matriculados. Concluímos com um questionamento sobre as diferenças formativas de um psicólogo graduado na capital daquele educado em uma instituição interiorizada.

Palavras-chave: formação do psicólogo; base de dados; revisão sistemática.
\end{abstract}

\section{CONSIDERATIONS ABOUT THE PSYCHOLOGIST FORMATION IN BRAZIL: SYSTEMATIC REVIEW}

\begin{abstract}
We aimed to analyze the current productions about psychologist formation in SciELO and PePSIC bases, according to a systematic review of 118 articles, categorized in year, periodical, authorship, affiliation, region, type of research, method, and subject. The results show: an increase in of productions in this decade; concentration of publications in the journal Psychology: Science and Profession; wide variety of authors and affiliations, with quite a lot of productions in the southeast; preponderance of empirical methodologies that use documentary analysis; prevalence of themes related to the scientific-academic formation. We indicate that there is a dispersion about the theme what a psychologist formation would be. There are many scholars who make momentary forays about the subject. There is a need for more discussions about the psychologist formation in Brazilian countryside, where currently concentrate the most of enrolled students. We conclude questioning about the formative differences of a psychologist graduated in the capital of that one educated in a countryside institution. Keywords: psychologist education; databases; literature review.
\end{abstract}




\title{
CONSIDERACIONES SOBRE LA FORMACIÓN DEL PSICÓLOGO EN BRASIL: REVISIÓN SISTEMÁTICA
}

\begin{abstract}
Resumen
Objetivamos analizar el estado actual sobre la formación del psicólogo en las bases SciELO/PePSIC, según una revisión sistemática de 118 artículos, clasificados como año, periódico, autoría, afiliación, región, tipo de investigación, método y tema. Los resultados muestran: aumento de la producción en esta década; concentración de publicaciones en la revista Psicologia: Ciência e Profissão; amplia variedad de autores y afiliaciones, con prominencia de las producciones en el sudeste; preponderancia de metodologías empíricas que utilizan análisis de documentos; prevalencia de temas relacionados a la formación académico-científica. Sugerimos que hay una dispersión sobre lo que sería la formación del psicólogo. Hay muchos estudiosos que hacen incursiones puntuales sobre el tema. Se necesitan más discusiones sobre la formación en los interiores brasileños, que actualmente concentran la mayoría de los estudiantes matriculados. Concluimos con un cuestionamiento sobre las diferencias formativas de un psicólogo graduado en la capital de aquel educado en una institución interiorizada.

Palabras clave: formación del psicólogo; base de datos; revisión sistemática.
\end{abstract}

\section{INTRODUÇÃO}

O tema da formação do psicólogo tem se constituído como um profícuo campo de pesquisas e discussões, desde a regulamentação da profissão no Brasil, pela Lei 4.118 de 1962, até os dias atuais. Com a expansão do ensino superior e o aumento de cursos de graduação em Psicologia, disseminados em diversas cidades, ampliou-se a produção de conhecimento sobre o tema nos âmbitos acadêmicos e profissionais. Com efeito, em 2004, as Diretrizes Nacionais de Educação delinearam uma regulamentação na graduação em Psicologia, em substituição ao Currículo Mínimo, com o intento de promover uma perspectiva de formação profissional mais ampla ante as transformações do mercado de trabalho (Ferreira Neto, 2010; Costa et al., 2012; Rudá, Coutinho, \& Almeida Filho, 2015).

Nesse sentido, o ano de 2004 foi marcante para o campo da formação do psicólogo, pois houve uma ampliação dos conhecimentos psicotécnicos, clínicos, escolares e organizacionais para um compromisso social, de modo a incluir atuações nas políticas públicas, no Sistema Único de Saúde (SUS) e no Sistema Único de Assistência Social (SUAS) (Ferreira Neto, 2004, 2017; Ministério do Desenvolvimento Social e Combate à Fome, 2007). Nos cursos de graduação em Psicologia, essa mudança atuou em conjunto com a influência da Lei de Diretrizes e Bases da Educação Nacional (LDB), de 1996 (Ministério da Educação, 1996), refletindo, conforme Bernardes (2004): 1) na lógica de um núcleo comum (capacitação básica) de componentes curriculares que culminam na oferta de ênfases, cuja escolha de uma aprofundará alguma perspectiva profissional de atuação do psicólogo; 2) na geração de habilidades e competências, além da aquisição de conhecimentos psicológicos e 3) no aumento de estágios básicos (dispostos nos núcleos comuns) e profissionalizantes (disponíveis nas ênfases oferecidas). 
Tais movimentos foram influentes no processo de modificação do modelo formativo em Psicologia e proporcionaram estudos voltados para os aspectos singulares remetentes às alterações ocorridas nessa esfera educacional. Com esse desenvolvimento, algumas pesquisas e publicações de revisões foram incensadas, de maneira a organizarem alguns entendimentos sobre a produção científica presente no campo da formação do psicólogo (Pardo, Mangieri, \& Nutti, 1998; Yamamoto, Souza, \& Yamamoto, 1999; Witter \& Ferreira, 2005; Costa, Costa et al., 2012; Costa, Amorin, Pessanha, \& Yamamoto, 2012).

Destarte, com a intenção de contribuir com esse movimento, objetivamos analisar o estado corrente de produções de conhecimento sobre artigos relacionados ao campo da formação do psicólogo no Brasil, com suporte em uma revisão sistemática sobre as bases de dados do Scientific Electronic Library Online (SciELO) e do Portal de Periódicos Eletrônicos em Psicologia (PePSIC). Para tal realização, averiguamos no material selecionado características referentes ao ano de publicação, periódico, autoria, filiação institucional, região, tipo de pesquisa, métodos empregados e o tema abordado pelos estudos.

Salientamos que não constituiu pretensão de nosso trabalho aquilatar uma avaliação final sobre a circulação de artigos sobre a formação do psicólogo e dos seus autores. Tampouco intencionamos avaliar a qualidade/quantidade do que foi produzido em termos de artigos, dado que esta pesquisa se propõe a tecer um juízo parcial do estado atual de produções nas aludidas bases, com vias a apontar algumas inferências/discussões possíveis ao cenário nacional, a partir dos resultados obtidos.

\section{MÉTODO}

A coleta e análise dos dados ocorreram mediante revisão sistemática de artigos publicados em periódicos nacionais que versaram estudos sobre a formação do psicólogo. A revisão sistemática tem como desígnio a organização e investigação de obras sobre uma mesma problemática, as quais se encontram dispersas em periódicos variados. As etapas-guias adotadas obedeceram aos pressupostos metodológicos postulados por Costa e Zoltowski (2014), os quais se encontram descritos a seguir.

Inicialmente, formulamos a seguinte indagação: qual o estado corrente da produção científica acerca da formação do psicólogo que circula em periódicos nacionais? Com a finalidade de responder a essa questão, elegemos as bases de dados do SciELO e do PePSIC. Ressaltamos que escolhemos nos restringir a esses indexadores pelos seguintes motivos: o SciELO é um banco de dados virtual de periódicos científicos bastante popular no Brasil, em razão de sua política de indexação de várias revistas, oriundas de áreas diversas, e de acesso aberto (gratuito) no País e em outros 12 países ibero-americanos, mais Portugal e a África do Sul; o SciELO computa mais de um milhão de acessos diários e é 
considerado, pela United Nations, Educational, Scientific and Cultural Organization (UNESCO), o maior provedor de periódicos indexados e de acesso aberto do Mundo (Packer, Cop, Luccisano, Ramalho, \& Spinak, 2014); o PePSIC, por sua vez, é uma fonte da Biblioteca Virtual em Saúde - Psicologia da União Latino-Americana de Entidades de Psicologia (BVS-PSi ULAPSI), que utiliza o mesmo sistema de dados do SciELO e, também, possui uma política de acesso aberto, concentrada somente na divulgação dos periódicos de Psicologia. Atualmente, o PePSIC tem distribuição em 10 países, além do Brasil. Por isso, avaliamos o SciELO e o PePSIC como fontes de dados úteis a nossa pesquisa, pois ambos têm representatividade na circulação de artigos científicos na Psicologia brasileira.

Nas duas bases utilizamos o índice de assuntos como modalidade de pesquisa, examinando os seguintes termos: Formação em psicologia; Formação do psicólogo; Ensino da psicologia; Formação do psicoterapeuta; Formação profissional em psicologia; Formação de psicólogo; Ensino de psicologia; e Formação educacional. Esta etapa de coleta ocorreu sem o cruzamento de descritores, prezando apenas pelas informações obtidas individualmente a partir de cada descritor. Cada texto foi lido com base no título, resumo e palavraschave.

Utilizamos os seguintes critérios de inclusão sobre os artigos observados: ter sido publicado em um periódico nacional; e ter discutido em seu conteúdo questões relacionadas à formação do psicólogo - sejam elas teóricas, curriculares, concernentes à atuação ou de pesquisa. Os artigos repetidos foram descartados e contabilizados apenas uma vez. A delimitação temporal da coleta comportou o período de 1996, ano da publicação mais antiga minutada, até 2015. Considerando que a coleta e tabulação dos dados ocorreram entre os meses de outubro de 2016 a fevereiro de 2017, salientamos que as publicações referentes ao ano de 2016 foram descartadas por se tratar do ano corrente à coleta de dados, havendo, pois, alguns periódicos que não haviam publicado todos os volumes do ano em que ocorreu a compilação - o que limitou nossa coleta até 2015 . Com base nesses critérios, tornou-se possível o armazenamento de uma amostra bibliográfica representativa sobre a formação do psicólogo nas bases SciELO e PePSIC. Categorizamos a amostra selecionada segundo: ano, periódico, autoria, filiação institucional, região, tipo de pesquisa (teórico, empírico ou relato de experiência), método empregado e tema discutido. Subjacente a isso, procuramos compreender a conjuntura histórica-social relacionada à distribuição temporal da produção levantada, tentando dialogar com outras pesquisas.

Apresentamos, em seguida na Figura 1, o fluxograma que descreve o percurso adotado na pesquisa - plano de seleção e extração dos artigos que resultou no banco de dados finais $(\mathrm{N}=118)$. 


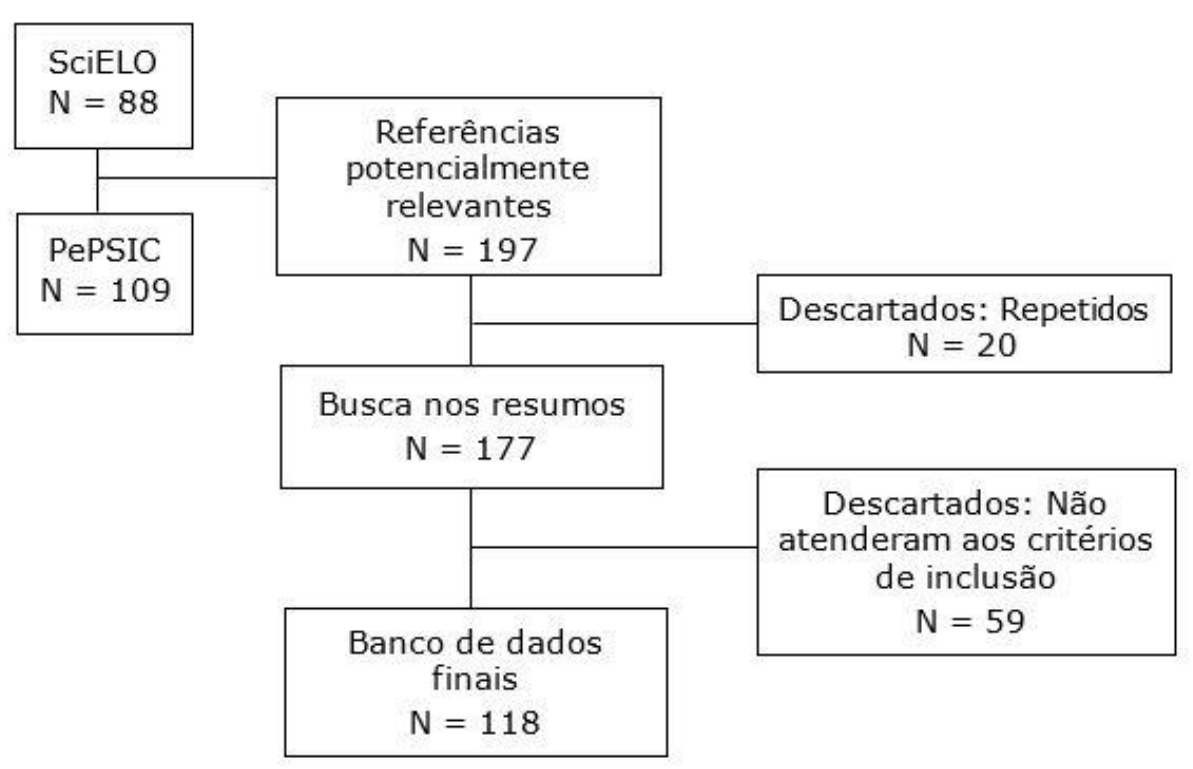

Figura 1. Fluxograma de etapas de seleção dos artigos na revisão sistemática.

Ressaltamos, destarte, que todo o processo de coleta foi realizado por juízes independentes, com a finalidade de reduzir possíveis vieses. Assim, nos casos de dúvidas relacionadas à tabulação de uma publicação, foram feitas ponderações conjuntas mediante leitura integral do artigo, para se chegar, finalmente, a um consenso. Acreditamos que esse percurso temporal e a amostra final $(N=118)$ foram suficientes para realizarmos inferências que descrevam o estado corrente de produção de conhecimento sobre o tema da formação do psicólogo nas bases de dados investigadas, como apresentaremos a seguir.

\section{RESULTADOS E DISCUSSÃO}

No PePSIC foram encontrados mais artigos $(N=109)$ em comparação ao SciELO $(N=88)$. Uma provável explicação disso é que as indexações do PePSIC são orientadas para o armazenamento e divulgação de conhecimentos psicológicos (PePSIC, 2017). No tocante à distribuição temporal das publicações, ilustrada na Tabela 1, expressa em seguida, verificou-se o período de produção geral de 1996 a 2015.

Tabela 1.

Distribuição temporal das publicações no período de 1996 a 2015.

\begin{tabular}{ccc}
\hline Ano & No de publicações & $\%$ \\
\hline 1996 & 1 & 0,85 \\
1997 & - & - \\
1998 & 2 & 1,69 \\
1999 & 4 & 3,39
\end{tabular}




\begin{tabular}{ccc}
2000 & 2 & 1,69 \\
2001 & 2 & 1,69 \\
2002 & 2 & 1,69 \\
2003 & 2 & 1,69 \\
2004 & 4 & 3,39 \\
2005 & 1 & 0,85 \\
2006 & 4 & 3,39 \\
2007 & 4 & 3,39 \\
2008 & 8 & 6,78 \\
2009 & 7 & 5,93 \\
2010 & 12 & 10,17 \\
2011 & 14 & 11,86 \\
2012 & 14 & 11,86 \\
2013 & 9 & 7,63 \\
2014 & 14 & 11,86 \\
2015 & 12 & 10,17 \\
Total & 118 & 100 \\
\hline
\end{tabular}

No ínterim de 1996 a 2007, constatamos certa estabilidade de produções, com exceção apenas do ano de 1997, que não apresentou publicações sobre o tema. Foi perceptível um aumento significativo a partir da década de 2010, que apresentou, em cinco anos, 63,56\% ( $N=75)$ do total das produções. Inferimos que esse crescimento pode estar relacionado à expansão da oferta de programas de pós-graduação, que, consoante aos estudos avaliativos de Cirani, Campanario e Silva (2015), minutam uma evolução quantitativa e qualitativa, no período de 1998 a 2011.

A partir de 2008, percebe-se um período de aumento das publicações. Segundo inferimos, esse fato possivelmente se relaciona com a ampliação do acesso ao ensino stricto sensu, ocorrido em meados da década de 2000 (Mancebo, Valle \& Martins, 2015). Outra inferência sobre esse aumento decorre da implantação das novas Diretrizes Curriculares Nacionais (DCN), em 2004 (Conselho Nacional de Educação, 2004). Ressalta-se que o estabelecimento das DCN's ocorreu apenas quatro anos antes do período analisado, ou seja, entre 2004-2008. Tal estabelecimento, segundo Cury e Ferreira Neto (2015), atualiza os modos de formar psicólogos, com base em um compromisso ético para atuar e intervir na realidade social, através da integração de habilidades e competências, extrapolando a lógica anterior de conteúdos disciplinares específicos e isolados. Nesse sentido, esse fenômeno pode ter influenciado o aumento de produções, realizadas com o intuito de compreender as modificações na formação do psicólogo decorrentes dessa implantação. 
Ainda referente ao período das publicações, indicamos que os dados obtidos em nossa pesquisa corroboram com o estudo de Costa, Costa et al. (2012), que abrangeu um número maior de banco de dados e analisou teses e dissertações. Os mencionados autores encontraram publicações datadas anteriormente a 1975 e observaram um crescimento considerável de produções a partir de 1990. Apoiando-nos nesse estudo e em nossos resultados, inferimos que esse crescimento, impulsionado na década de 1990, e com aumento visível no cenário atual, principalmente a partir do ano de 2010, corresponde à ampliação do número de matrículas em Institutos de Ensino Superior (IES). Ponderamos que esse fenômeno é decorrente da consolidação dos governos conduzidos por presidentes da República eleitos pelo voto direto. Esses governos, segundo Mancebo et al. (2015), utilizaram de programas de desenvolvimento visando à aderência da população aos cursos de ensino superior, sejam eles através de iniciativa pública ou privada.

Com efeito, o número de matrículas em cursos de graduação presenciais de Psicologia, em 2015, segundo dados do Instituto Nacional de Estudos e Pesquisas Educacionais Anísio Teixeira - INEP (2016), perfez o total de 224.916 alunos, conforme descrito na Tabela 2 , expressa a seguir.

Tabela 2.

Total de alunos matriculados em cursos de graduação presenciais em psicologia, em 2015.

\begin{tabular}{|c|c|c|c|c|c|}
\hline \multirow{3}{*}{ Tipo de Formação } & \multicolumn{5}{|c|}{ Matrículas em Cursos de Graduação Presenciais } \\
\hline & \multicolumn{3}{|c|}{ Pública } & \multirow{2}{*}{ Privada } & \multirow{2}{*}{ Total } \\
\hline & Federal & Estadual & Municipal & & \\
\hline $\begin{array}{l}\text { Professor de } \\
\text { Psicologia }\end{array}$ & 448 & 174 & - & 804 & 1.426 \\
\hline Psicologia & 16.081 & 5.249 & 4.836 & 197.324 & 223.490 \\
\hline Total & 16.529 & 5.423 & 4.836 & 198.128 & 224.916 \\
\hline
\end{tabular}

Nota. A Tabela é de elaboração própria, baseada nos dados do INEP (2016).

Houve, pois, um grande crescimento, se comparado à pesquisa do INEP de 2009, apresentada no estudo de Macedo e Dimenstein (2011), que revela que durante aquele ano, 65.508 vagas foram ofertadas nos cursos de graduação em Psicologia. Para além dos números de alunos matriculados, apontados na Tabela 2, esses dados nos mostram que é necessário frisar a importância das políticas de expansão e interiorização do ensino superior. Estas foram iniciadas em 2001, no governo de Fernando Henrique Cardoso, onde houve a implantação do Programa de Financiamento Estudantil (FIES), que continuou, em 2003, com o governo federal de Luís Inácio Lula da Silva, através do Programa Universidade para Todos (ProUni), financiador do acesso à educação superior pelo setor 
privado, via FIES, e do setor público, via Programa de Apoio a Planos de Reestruturação e Expansão das Universidades Federais (REUNI), em 2007.

Como apresentado na Tabela 2, o número de alunos matriculados em instituições privadas é superior ao do ensino superior público, o que é consoante aos resultados obtidos pelos estudos de Chaves e Amaral (2016), os quais demonstram que, mesmo com a existência dos períodos expansionistas educacionais do setor público, há uma predominância no número de instituições e matrículas no setor privado. Ou seja, esta realidade persistiu a despeito do aumento do número de instituições públicas superarem o aumento do campo privado, entre 2003-2014 (Chaves \& Amaral, 2016). Entretanto, a política de governo voltada ao investimento no setor público possibilitou maiores incentivos à pesquisa científica tanto em nível de graduação quanto de pós-graduação, as quais foram fundamentais para desenvolver o conhecimento científico brasileiro (Mancebo et al., 2015). Com efeito, notamos que a predominância de matrículas em cursos de graduação em Psicologia nas instituições de ensino privado diverge, segundo os dados levantados em nossa pesquisa, da proporção de produções que se voltam ao estudo do processo formativo dos estudantes nesse âmbito educacional. Ao analisar os resumos das publicações minutadas, observamos que apenas cinco artigos se relacionam com as características formativas institucionais privadas. Assim, ajuizamos que a formação do psicólogo em faculdades privadas, ainda, é um campo com potencial para aprofundamento em pesquisas.

Para além dos números de alunos matriculados, apontados na Tabela 2, esses dados nos mostram que é necessário frisar a importância das políticas de expansão e interiorização do ensino superior propostas pelo governo federal de Luís Inácio Lula da Silva, a exemplo do Programa de Apoio a Planos de Reestruturação e Expansão das Universidades Federais (REUNI). Destarte, consoante Mancebo et al. (2015), observamos que maioria das produções científicas nacionais é constituída dentro das universidades públicas, mais especificamente, nos cursos de pós-graduação. Dessa forma, a política de governo voltada ao investimento no setor público possibilitou maiores incentivos à pesquisa científica em nível de graduação ede pós-graduação, as quais foram fundamentais para desenvolver o conhecimento científico brasileiro.

Com o aumento de publicações sobre a formação do psicólogo, inventariamos os autores e coautores que escreveram sobre o tema (272 no total) nas bases SciELO e PePSIC. Estabelecemos um ranque dos pesquisadores mais produtivos nessas bases, são eles: Neuza Maria de Fátima Guareschi ( $\mathrm{N}=$ $5 ; 1,67 \%)$; Oswaldo Hajime Yamamoto ( $N=4 ; 1,34 \%)$; Carolina dos Reis ( $N=$ 3; $1 \%)$; João Leite Ferreira Neto $(\mathrm{N}=3 ; 1 \%)$; Marilene Proença Rebello de Souza $(\mathrm{N}=3 ; 1 \%)$; Henrique Caetano Nardi $(\mathrm{N}=3 ; 1 \%)$; e Silvia Maria Cintra da Silva $(\mathrm{N}=3 ; 1 \%)$. Os demais autores encontrados $(\mathrm{N}=265 ; 91,99 \%)$ produziram de um a dois artigos. Tais dados demonstram, pois, uma variedade 
de estudiosos que se debruçaram sobre a temática. Curiosamente, entre aqueles autores que ocupam o ranque dos sete mais producentes, apenas três ( $O$. Yamamoto, J. Ferreira Neto e S. da Silva) afirmam em seus currículos lattes dispostos em um portal mantido pelo Conselho Nacional de Desenvolvimento Científico e Tecnológico (CNPq) - serem pesquisadores voltados para o campo da formação do psicólogo.

Desse modo, inferimos em nossa pesquisa, que poucos autores brasileiros têm, especificamente, como objeto de estudo central a formação do psicólogo, sendo a maioria das publicações pontuais sobre o tema. Ressaltamos que esse dado, também, foi encontrado na pesquisa de Costa, Costa et al. (2012), o qual aponta a existência de poucos aprofundamentos teóricos nas publicações sobre a temática. Em outra pesquisa, via plataforma lattes, realizada por Costa, Amorin et al. (2012) sobre o perfil dos autores que estudam a profissão do psicólogo no Brasil, igualmente, revelou-se a eventualidade dessa temática, dado que muitos autores pesquisados não assumem esse assunto como central. Essa realidade corrobora com os nossos achados nas bases SciELO e PePSIC. Ao que nos parece, conquanto o tema da formação do psicólogo interesse a muitos e gere incursões, poucos desenvolvem um percurso maior de pesquisas e produção de conhecimento sobre o tema.

Em se tratando das filiações institucionais anunciadas pelos autores dos artigos minutados, encontramos um total de 79 instituições que foram expressas 304 vezes. As instituições brasileiras referenciadas computaram 94,94\% ( $N=$ 75) do total; e parte dos autores afirmaram filiações em mais de uma instituição. Em razão disso, o número final de universidades citadas superou a quantidade anterior. As instituições internacionais ( $\mathrm{N}=4 ; 5,33 \%)$ também apareceram, sendo elas: UNr-Conicet (Argentina); Universidade de Deusto (Espanha); Universidad Católica de Asunción (Paraguai); e Universidad de la Frontera (Chile). Contudo, não distribuímos essas filiações estrangeiras na Tabela 3, expressa em seguida, por elas não estarem situadas nas regiões brasileiras.

Tabela 3.

Filiações institucionais dos autores e coautores, por região brasileira.

\begin{tabular}{cccccc}
\hline Região & $\begin{array}{c}\text { Filiação } \\
\text { institucional }\end{array}$ & $\begin{array}{c}\text { No de } \\
\text { aparições }\end{array}$ & $\%$ & $\begin{array}{c}\text { Total de } \\
\text { aparições }\end{array}$ & $\%$ \\
\hline \multirow{2}{*}{ Norte } & UNIR & 4 & 1,32 & 7 & 2,30 \\
& UNESC & 3 & 0,99 & & \\
& UFBA & 17 & 5,59 & & \\
Nordeste & UFRN & 16 & 5,26 & & \\
& UFPI & 10 & 3,29 & 61 & \\
& UNIFOR & 6 & 1,97 & & \\
& UFS & 3 & 0,99 & & \\
\hline
\end{tabular}




\begin{tabular}{|c|c|c|c|c|c|}
\hline & $\begin{array}{c}\text { Demais } \\
\text { instituições }\end{array}$ & 9 & 2,97 & & \\
\hline \multirow[b]{2}{*}{ Centro-Oeste } & UFG & 9 & 2,96 & \multirow[b]{2}{*}{15} & \multirow[b]{2}{*}{4,93} \\
\hline & $\begin{array}{c}\text { Demais } \\
\text { instituições }\end{array}$ & 6 & 1,97 & & \\
\hline \multirow{14}{*}{ Sudeste } & USP & 35 & 11,51 & \multirow{14}{*}{141} & \multirow{14}{*}{46,38} \\
\hline & UNIFESP & 10 & 3,29 & & \\
\hline & UNESP & 9 & 2,96 & & \\
\hline & PUC - CAMPINAS & 9 & 2,96 & & \\
\hline & UFMG & 8 & 2,63 & & \\
\hline & UFU & 7 & 2,30 & & \\
\hline & UFTM & 6 & 1,97 & & \\
\hline & UFES & 6 & 1,97 & & \\
\hline & USF & 6 & 1,97 & & \\
\hline & UFF & 6 & 1,97 & & \\
\hline & UFJF & 4 & 1,32 & & \\
\hline & UNIP & 4 & 1,32 & & \\
\hline & PUC - MG & 4 & 1,32 & & \\
\hline & $\begin{array}{c}\text { Demais } \\
\text { instituições }\end{array}$ & 27 & 8,88 & & \\
\hline \multirow{8}{*}{ Sul } & UFRGS & 19 & 6,25 & \multirow{8}{*}{74} & \multirow{8}{*}{24,34} \\
\hline & PUC - RS & 11 & 3,62 & & \\
\hline & UFSC & 7 & 2,30 & & \\
\hline & $\begin{array}{c}\text { Faculdades } \\
\text { Integradas } \\
\text { Taquara }\end{array}$ & 6 & 1,97 & & \\
\hline & UEM & 5 & 1,64 & & \\
\hline & UNIFIL & 4 & 1,32 & & \\
\hline & UEL & 3 & 0,99 & & \\
\hline & $\begin{array}{c}\text { Demais } \\
\text { instituições }\end{array}$ & 19 & 6,25 & & \\
\hline Total & 75 & 298 & 98,02 & 298 & 98,02 \\
\hline
\end{tabular}

Das 75 universidades nacionais atribuídas às publicações, 35 são instituições públicas e 40 são da rede privada. Destarte, esses resultados contrastam com a concepção de que a educação superior ofertada pelas instituições privadas se refere a uma dissociação do ensino para com a pesquisa e extensão (Chaves \& Amaral, 2016). Além disso, no estudo de Mancebo et al. (2015), observa-se que, diante da expansão do ensino superior, a maioria das produções científicas nacionais é constituída dentro das universidades públicas, mais especificamente, nos cursos de pós-graduação, afirmativa que não se aplicou à temática da formação do psicólogo. 
Em relação à localização geográfica, notamos que a região Sudeste demonstrou predominância de produções sobre o tema, com base na quantidade de instituições citadas ( $N=141 ; 46,38 \%$ ), além de apresentar a instituição mais produtiva, a Universidade de São Paulo - USP ( $N=35 ; 11,51 \%)$, que possivelmente obteve esse resultado em vista de possuir cinco programas de pós-graduação em Psicologia. A Região Sul, também, comportou um grande número de publicações ( $\mathrm{N}=74 ; 24,34 \%$ ), e a Universidade Federal do Rio Grande do Sul (UFRGS) é a instituição que mais filiou produções na região ( $N=$ $19 ; 6,25 \%)$, apresentando outra oferta significativa de três programas de pósgraduação em Psicologia, que pode ter gerado esse resultado. Em seguida, encontramos a região Nordeste $(\mathrm{N}=61 ; 20,07 \%)$, com destaque para a Universidade Federal da Bahia - UFBA ( $N=17 ; 5,59 \%)$. Frisamos que alcunhamos a filiação "Demais instituições" àquelas universidades que somente expressaram uma ou duas publicações em relação ao tema.

De acordo com os resultados apresentados na Tabela 3, percebemos que a região Sudeste abrangeu, aproximadamente, o dobro de produções em relação à região Sul. A USP produziu, também, a mesma média em relação à UFRGS. As regiões Sul e Nordeste expressaram resultados próximos no tocante à quantidade de aparições, não havendo diferenças significativas quando comparadas as duas universidades mais producentes localizadas nestas regiões UFRGS e UFBA. Esses dados apontam para uma diminuição significativa das diferenças regionais referentes às produções minutadas. Comparando esses achados aos resultados da pesquisa de Costa, Costa et al. (2012), percebemos que eles encontraram distribuições regionais muito discrepantes na produção científica relacionada ao tema. Identificamos, em nosso estudo e no deles, uma grande concentração de estudos referentes ao tema desse artigo na região Sudeste.

Nesse sentido, apesar dos avanços da produção científica nas regiões Norte e Nordeste, percebemos diferenças significativas na distribuição geográfica dos estudos. A despeito disto, ressaltamos a importância das políticas de expansão do Ensino Superior para essas regiões; e reconhecemos que, mesmo diante das mudanças conjunturais ocasionadas a partir dessas políticas, existem regiões que detêm a hegemonia da produção nos mais variados campos do saber. A esta estruturação na construção do saber científico brasileiro, cabe bem à conceituação de zonas detentoras do saber, conforme definiu Costa, Costa et al. (2012).

Ao comparar as informações de nosso estudo com a pesquisa de Costa, Costa et al. (2012), notamos um aumento importante na quantidade de produções geradas nas regiões Norte, Centro-Oeste e Nordeste. Contudo, salientamos que em nosso estudo foram consultadas apenas as bases PePSIC e SciELO, ao passo que a pesquisa retrocitada abrangeu uma quantidade maior de fontes. Ainda assim, é possível afirmar que o processo de expansão do ensino 
superior no Brasil se ramificou por meio de quatro tendências expressas, segundo Mancebo et al. (2015): 1) pelo aumento no número de IES com fins lucrativos; 2) pela expansão de vagas e cursos nas IES federais; 3) pela diferenciação de cursos, principalmente através do Ensino a Distância (EaD) e 4) pela expansão dos programas de pós-graduação. A partir disso, inferimos que ocorreu um movimento de disseminação dos cursos de Psicologia em todo território nacional, o qual gerou maior demanda de pesquisas e produções do conhecimento referentes à formação do psicólogo.

Um dado interessante diz respeito aos autores produtivos comparados à instituição mais producente, a USP. Nenhum dos autores brasileiros mais produtivos em nosso ranque está filiado a essa universidade. Esse dado corrobora, novamente, com o estudo de Costa, Costa et al. (2012), o qual constata que muitos pesquisadores se lançaram sobre o tema da Formação do Psicólogo de maneira pontual nas suas carreiras, de modo que há uma dispersão nesse campo de pesquisa com poucos autores que aprofundam essa temática.

Em relação à distribuição dos tipos de publicação, indicamos a predominância de produções de cunho empírico ( $N=65 ; 55,08 \%$ ), seguidos daquelas voltadas para discussões teóricas ( $\mathrm{N}=34 ; 28,81 \%)$, e, por último, àquelas referentes a relatos de experiência $(N=19 ; 16,10 \%)$. No estudo de Costa, Costa et al. (2012), por outro lado, houve uma maior concentração de relatos teóricos, ao passo que os autores teceram a seguinte crítica:

(...) a predominância de materiais produzidos individualmente, com caráter teórico/ensaio, bem como de autores com um único trabalho escrito sobre o assunto, reforçam a ideia de que o tema "formação do psicólogo" apresenta um campo de pesquisa disperso, em que as publicações de maior visibilidade são majoritariamente opinativas. Soma-se a isso o fato de que poucos são os pesquisadores com linhas de pesquisa sistematizadas relativas à temática (Costa, Costa et al., 2012, p. 136).

Cabe lembrar que em nosso estudo foram levantados apenas artigos publicados em periódicos. Esses meios de divulgação científica, segundo ajuizamos, seguem uma tendência de maior valorização de estudos empíricos. Conforme apontaram Costa, Costa et al. (2012), a necessidade de sobrepor artigos empíricos a teóricos ocorre em razão da valoração das atividades que objetivam entender como ocorre o processo de formação do psicólogo, visando o aperfeiçoamento da prática. Nesse sentido, observamos tal sobreposição em nosso estudo.

Os três métodos empíricos de coleta de dados mais utilizados pelos autores foram análise documental ( $\mathrm{N}=21 ; 21,43 \%)$, entrevista semidirigida ( $\mathrm{N}$ $=17 ; 17,35 \%)$ e questionário de perguntas fechadas $(\mathrm{N}=08 ; 8,16 \%)$. $\mathrm{A}$ predominância de análise documental, conforme percebemos, acontece mediante a presença de inúmeras atividades voltadas para a exploração das matrizes curriculares, ementas e projetos pedagógicos dos cursos de Psicologia. Assim, a 
análise documental se estabelece como uma tendência metodológica de aprofundamento e questionamento de como se gera institucionalmente a formação do psicólogo. Essa perspectiva, também, foi elucidada na pesquisa de Costa, Costa et al. (2012). As presenças, também significativas, de entrevistas e questionários, segundo pensamos, referem-se ao fato desses instrumentos serem de ampla utilização para a obtenção de informações de psicólogos que vivenciam o processo formativo.

Aos analisar as concepções teóricas e empíricas abordadas pelas produções, em geral, percebemos uma presença de discussões que buscam compreender os âmbitos formativos da graduação em Psicologia, sejam pela via das estruturas curriculares, instrumentos formativos (por exemplo, laboratórios) ou experiências práticas. Entretanto, os focos são direcionados para materiais (por exemplo, inventários), localizações geográficas e áreas/campos de atuação, enfocando, portanto, os aspectos que estão presentes no processo formativo de psicólogos, sem se deter, especificamente, em definições teóricas e conceituais acerca do que seria a formação do psicólogo.

Além disso, investigamos os 38 periódicos que publicaram os artigos levantados, conforme apontamos, em seguida, na Tabela 4, em que o termo "Demais periódicos" remete àqueles que publicaram de 1 a 3 artigos.

Tabela 4.

Distribuição dos periódicos segundo o número de artigos publicados.

\begin{tabular}{ccc}
\hline Periódico & $\begin{array}{c}\text { No de artigos } \\
\text { publicados }\end{array}$ & $\%$ \\
\hline $\begin{array}{c}\text { Psicologia: Ciência e Profissão } \\
\text { Revista Quadrimestral da Associação }\end{array}$ & 29 & 24,58 \\
Brasileira de Psicologia Escolar e Educacional & 10 & 8,47 \\
Psicologia Ensino \& Formação & 9 & 7,63 \\
Temas em Psicologia & 8 & 6,78 \\
Avaliação Psicológica & 6 & 5,08 \\
Psicologia \& Sociedade & 6 & 5,08 \\
Demais periódicos & 50 & 42,38 \\
Total & 118 & 100 \\
\hline
\end{tabular}

Percebemos uma primazia do periódico Psicologia: Ciência e Profissão (PSP) ( $N=29 ; 24,58 \%$ ), que publicou algo próximo do triplo de artigos da segunda revista mais produtiva sobre o tema. Esta hegemonia pode estar relacionada à missão da PSP, que é contribuir para a difusão de conhecimentos científicos socialmente relevantes nas mais diversas áreas da Psicologia (Psicologia: Ciência e Profissão, 2017), possibilitando inúmeras publicações referentes à temática pesquisada. Indicamos, também, o lançamento de um volume especial da PSP, em 2012 ( $N=14 ; 11,86 \%$ ), um dos anos com o maior 
número de produções minutadas (segundo demonstramos anteriormente na Tabela 1) referentes à comemoração dos seus trinta anos de circulação, conjuntamente com os cinquenta anos de regulamentação da profissão do psicólogo no Brasil.

O segundo periódico com maior número de publicações foi a Revista Quadrimestral da Associação Brasileira de Psicologia Escolar e Educacional ( $\mathrm{N}=$ $10 ; 8,47 \%$ ) que tem por compromisso a divulgação de manuscritos ligados à reflexão crítica sobre a produção acadêmico-científica e relatos de pesquisas nas áreas de Psicologia Escolar e Psicologia Educacional (Psicologia Escolar e Educacional, 2017). O terceiro periódico, Psicologia: Ensino e Formação ( $N=09$; $7,63 \%$ ), apresenta como objetivo a propagação de conhecimento sobre o ensino e a formação em Psicologia, contemplando questões didáticas, de conteúdo, éticas, epistemológicas e metodológicas - considerando o que está ligado à formação do psicólogo e suas realidades sociais e históricas (Psicologia: Ensino e Formação, 2017).

No que concerne às temáticas discutidas pelos artigos analisados, encontramos discussões, em maior número, nos âmbitos da formação acadêmico-científica ( $N=31 ; 26,27 \%)$, da saúde $(N=18 ; 15,25 \%)$, de questões curriculares $(N=13 ; 11,02 \%)$ e da clínica ( $N=13 ; 11,02 \%)$. Em relação às temáticas referentes à formação acadêmico-científica e às questões curriculares, inferimos que a prevalência dessas discussões é explicada por uma preocupação com a compreensão e o desenvolvimento de estratégias educacionais de formação/ensino em Psicologia. Ressaltamos que isso, também, está presente nos achados de Costa, Costa et al. (2012), os quais perceberam que as maiores ocorrências temáticas estavam voltadas para a investigação dos currículos e das necessidades de suas mudanças, pelo desenvolvimento da formação científica, da ética profissional e da relação teoria e prática.

A saúde foi outra temática corrente nos artigos que levantamos, sendo um dos principais quesitos relacionados à atuação profissional. Percebemos isso perante as mudanças curriculares voltadas para uma maior circunscrição da atuação do profissional psicólogo nas políticas públicas, sobretudo, através do SUS (Ferreira Neto, 2017). Com a criação do SUS e da sua ampliação contínua, através da Estratégia de Saúde da Família, o campo da Saúde foi apresentado como possibilidade de trabalho para o psicólogo, o qual, egresso de uma formação voltada para o âmbito industrial, escolar e, principalmente, clínico, teve que aprender através da prática cotidiana (Ferreira Neto, 2004). O Núcleo de Apoio à Saúde da Família (NASF) é um exemplo de oportunidade de trabalho para o Psicólogo, haja vista à recomendação desse profissional para a composição da equipe mínima (Leite, Andrade, \& Bosi, 2013). Segundo Ferreira Neto (2010), existe, pois, uma tendência recente para moldar o processo formativo do psicólogo de acordo com as "práticas emergentes", a saber, as novas áreas de atuação do psicólogo decorrente das mudanças sociais e das 
políticas públicas que requerem novos conhecimentos e intervenções condizentes à realidade brasileira. Conforme esse panorama é possível identificar uma possível explicação para o montante considerável de discussões relacionadas à formação do psicólogo no campo da Saúde.

De acordo com Macedo e Dimenstein (2011), o número de psicólogos na rede pública aumentou de modo exponencial segundo a implementação de políticas públicas nas áreas da Saúde e da Assistência Social e Jurídica, cujo mercado de trabalho tem crescido, principalmente, em cidades de pequeno e médio porte. Esse investimento no setor público tem contribuído para o desenvolvimento dos interiores brasileiros, assim como as políticas de expansão e interiorização do ensino superior. Entretanto, notamos que, apesar desse crescimento, consoante os aludidos autores, poucos pesquisadores estão estudando a formação de psicólogos nos interiores do Brasil e suas diferentes realidades em comparação às capitais.

Macedo e Dimenstein (2011) apresentam alguns dados do INEP, obtidos em 2007, os quais diferenciam as matrículas dos cursos presenciais dos interiores e das capitais. Esses dados, relacionados às matrículas em cursos presenciais no Brasil, demonstram que 2.682.880 estudantes de IES foram matriculados nos interiores do País, computando mais da metade da amostra total de matriculados em cidades situadas nas capitais. Infelizmente, O INEP (2016) mais recente não catalogou o número de alunos matriculados em cursos presenciais. Contudo, podemos inferir que atualmente a maioria dos estudantes matriculados em IES cursa graduação nos interiores do País, pois o registro mais recente do INEP (2016) indica que de um total de 2.368 instituições de Ensino Superior, 1.523 estão localizadas fora das capitais. Nesse sentido, concordamos com Macedo e Dimenstein (2011) em relação ao apontamento de que a ampliação do mercado de trabalho para o psicólogo nas cidades de pequeno e médio porte, a partir de dispositivos públicos, possivelmente, desencadearam tamanha oferta de cursos de graduação em Psicologia nos interiores do Brasil. É necessário, pois, investigarmos mais a formação dos psicólogos nos interiores, em universidades públicas e privadas.

\section{CONSIDERAÇÕES FINAIS}

No transcurso do que foi exposto, ressaltamos que apesar da riqueza de reflexões que o tema da formação do psicólogo possa provocar, como objeto de estudo este se encontra disperso, havendo diversos entendimentos teóricos e empíricos sobre esse fenômeno. Como incursão profícua e pertinente, por um lado, o tema gera variadas produções de conhecimento nas bases de dados do SciELO e do PePSIC; por outro, poucos pesquisadores/autores demonstram percurso mais amplo e profundo sobre tal temática. 
Salientamos que o trabalho de revisão sistemática sobre a formação do psicólogo deve ser recorrente e incessantemente refeito, dialogando com outras pesquisas, suplementando-as de modo a expandir um entendimento sobre como esse conhecimento se desenvolve no Brasil. Assim, frisamos que o nosso trabalho deve ser visto com cautela e como parcial, dado que a nossa estratégia metodológica se remeteu somente a duas bases de dados, o que de certo modo restringe os nossos achados ao não englobar outras produções disponíveis em outras fontes. Outro limite se refere ao recorte de nos atermos somente a artigos publicados em periódicos. Existe, ainda, outro campo de produções acadêmicas sobre o tema que se encontra disponível em dissertações e teses que estão disponíveis no Banco de Teses da CAPES (outro banco de dados), que podem ser alvo de outra revisão sistemática.

A despeito disso, consideramos que os resultados ora obtidos possibilitaram alguns juízos que dialogaram com outros levantamentos (Chaves \& Amaral, 2016; Cirani et al., 2015; Costa, Amorin et al., 2012; Costa, Costa, et al., 2012; INEP, 2016; Macedo \& Dimenstein, 2011), por vezes se aproximando e valendo deles. As discussões, elencadas pelo o que os resultados nos provocaram, apontaram para um cenário nacional maior, que depara com o desenvolvimento da formação profissional para atuar nas políticas públicas e nos interiores do Brasil. Estes locais se desenvolvem como um recente e complexo campo de pesquisas e reflexões, ainda, em construção. Quais as diferenças formativas de um psicólogo que se forma em uma universidade estruturada na capital daquele que se forma numa IES recém-implementada em uma cidade de interior? Futuras pesquisas nos possibilitarão maior compreensão sobre isso.

\section{DECLARAÇÃO DE CONFLITO DE INTERESSES}

Não há conflito de interesses.

\section{REFERÊNCIAS}

Bernardes, J. (2004). O debate atual sobre a formação em psicologia no Brasil: Permanências, rupturas e cooptações nas políticas educacionais. (Tese de Doutorado). Pontifícia Universidade Católica de São Paulo, São Paulo. Recuperado em 30 de abril de 2019, de https://tede2.pucsp.br/bitstream/handle/17243/1/Jefferson $\% 20$ de $\% 20$ Souz a\%20Bernardes.pdf.

Chaves, V., \& Amaral, N. (2016). Política de expansão da educação superior no Brasil - o PROUNI e o FIES como financiadores do setor privado. Educação em Revista, 32(4), 49-72. doi:10.1590/0102-4698162030

Cirani, C., Campanario, M., \& Silva, H. (2015). A evolução do ensino da pósgraduação senso estrito no Brasil: Análise exploratória e proposições para 
pesquisa. Avaliação: Revista da Avaliação da Educação Superior (Campinas), 20(1), 163-187. doi:10.590/S1414-40772015000500011

Conselho Nacional de Educação. (2004). Resolução no 8 de 07 de Maio de 2004. Institui as Diretrizes Curriculares Nacionais para os Cursos de Graduação em Psicologia. Brasília: Diário Oficinal da União. Recuperado em 30 de abril de 2019, de http://portal.mec.gov.br/cne/arquivos/pdf/rces08 04.pdf.

Costa, A., \& Zoltowski, A. (2014). Como escrever um artigo de revisão sistemática. In S. Koller, M. Couto, \& J. Hohendorff (Eds.), Manual de produção científica (pp. 55-70). Porto Alegre, RS: Penso.

Costa, J., Costa, A., Lima, F., Seixas, P., Pessanha, V., \& Yamamoto, O. (2012). A produção científica sobre a formação do psicólogo no Brasil. Psicologia em Pesquisa, 6(2), 130-138. doi:10.5327/Z1982-12472012000200006

Costa, J., Amorin, K., Pessanha, V., \& Yamamoto, O. (2012). Quem estuda a formação do psicólogo no Brasil? Arquivos Brasileiros de Psicologia, 64(2), 02-18. Recuperado em 30 de abril de 2019, de http://pepsic.bvsalud.org/scielo.php?script=sci arttext\&pid=S1809$52672012000200002 \& \operatorname{lng}=p t \& t \operatorname{lng}=p t$.

Cury, B., \& Ferreira Neto, J. (2015). Do currículo mínimo às diretrizes curriculares: Os estágios na formação do psicólogo. Psicologia em Revista, 20(3). doi: 10.5752/P.1678-9523.2014V20N3P494

Ferreira Neto, J. (2004). A formação do psicólogo: Clínica, social e mercado. São Paulo: Escuta.

Ferreira Neto, J. (2010). Uma genealogia da formação do psicólogo brasileiro. Memorandum, 18, 130-142. Recuperado em 30 de abril de 2019, de http://www.fafich.ufmg.br/ memorandum/a18/ferreiraneto01.pdf.

Ferreira Neto, J. (2017). Psicologia, políticas públicas e o SUS. São Paulo: Escuta; Belo Horizonte: FAPEMIG.

Instituto Nacional de Estudos e Pesquisas Educacionais Anísio Teixeira - INEP. (2016). Sinopse estatística da educação superior 2015. Brasília: INEP. Recuperado em 30 de abril de 2019, de http://download.inep.gov.br/informacoes estatisticas/sinopses estatisticas/ sinopses educacao superior/sinopse educacao superior 2015.zip.

Leite, D., Andrade., A., \& Bosi, M. (2013). A inserção da Psicologia nos Núcleos de Apoio à Saúde da Família. Physis: Revista de Saúde Coletiva, 23(4), 1167-1187. doi:10.1590/S0103-73312013000400008.

Macedo, J, \& Dimenstein, M. (2011). Expansão e interiorização da Psicologia: Reorganização dos saberes e poderes na atualidade. Psicologia: Ciência e Profissão, 31(2), 296-313. doi:10.1590/S1414-98932011000200008

Mancebo, D., Valle, A., \& Martins, T. (2015). Políticas de expansão da educação superior no Brasil 1995-2010. Revista Brasileira de Educação, 20(80), 3150. doi: $10.1590 /$ S1413-24782015206003 
Ministério da Educação. (1996). Lei no 9.394 de 20 de dezembro de 1996 Estabelece as diretrizes e bases da educação nacional. Brasília: Diário Oficial da União. Recuperado em 30 de abril de 2019, de http://www.planalto.gov.br/Ccivil 03/leis/L9394.htm.

Ministério do Desenvolvimento Social e Combate à Fome (2007). Norma Operacional Básica de Recursos Humanos do SUAS (NOB-RH/SUAS). Brasília.

Packer, A., Cop, N., Luccisano, A., Ramalho, A., \& Spinak, E. (Eds.). (2014). SciELO - 15 anos de acesso aberto e comunicação científica. Paris: UNESCO.

Pardo, M., Mangieri, R., \& Nucci, M. (1998). Construção de um modelo para análise da formação profissional do psicólogo. Psicologia: Ciência e Profissão, 18(3), 14-21. doi:10.1590/S1414-98931998000300003

PePSIC. (2017). PePSIC - critérios para inclusão de revistas. Recuperado em 30 de abril de 2019, de http://pepsic.bvsalud.org/.

Psicologia: Ciência e Profissão. (2017). Sobre nós. Recuperado em 30 de abril de 2019, de http://www.scielo.br/revistas/pcp/paboutj.htm.

Psicologia: Ensino e Formação. (2017). Sobre nós. Recuperado em 30 de abril de 2019, de http://pepsic.bvsalud.org/revistas/pef/paboutj.htm.

Psicologia Escolar e Educacional. (2017). Sobre nós. Recuperado em 30 de abril de 2019, de http://www.scielo.br/revistas/pee/paboutj.htm.

Rudá, C., Coutinho, D., \& Almeida Filho, N. (2015). Formação em psicologia no Brasil: O período do currículo mínimo (1962-2004). Memorandum, 29, 5895. Recuperado em 30 de abril de 2019, de http://www.fafich.ufmg.br/memorandum/wpcontent/uploads/2015/11/rudacoutinhoalmeidafilho01.pdf.

Witter, G., \& Ferreira, A. (2005). Formação do psicólogo hoje. In Conselho Federal de Psicologia (Ed.), Psicólogo brasileiro: construção de novos espaços (pp. 15-39). Campinas: Alínea.

Yamamoto, O., H., Souza, C., \& Yamamoto, M. (1999). A produção científica na psicologia: Uma análise dos periódicos brasileiros no período 1990-1997. Psicologia: Reflexão e Crítica, 12(2), 549-565. doi:10.1590/S010279721999000200019 
Sobre os autores

Bianca Veiga Prates é graduada em Psicologia pelo Instituto Multidisciplinar em Saúde da Universidade Federal da Bahia, Vitória da Conquista. E-mail:

biancaveiga11@hotmail.com

Ellen Araújo Lima Feitosa é graduada em Psicologia pelo Instituto Multidisciplinar em Saúde da Universidade Federal da Bahia, Vitória da Conquista. Especialista em Serviço Social em Saúde, Seguridade Social e Políticas Públicas pela UNIGRAD. E-mail: ellenalf93@gmail.com

Paulo Souza Monteiro é graduado em Psicologia pelo Instituto Multidisciplinar em Saúde da Universidade Federal da Bahia, Vitória da Conquista. Especialista em Saúde Pública pela Faculdade de Guanambi. E-mail:

paulinhonsapeg@hotmail.com

Paulo Coelho Castelo Branco é Coordenador e Professor Programa de PósGraduação em Psicologia da Saúde do Instituto Multidisciplinar em Saúde da Universidade Federal da Bahia, Vitória da Conquista. Doutor em Psicologia pela Universidade Federal de Minas Gerais. E-mail: pauloccbranco@gmail.com

A contribuição de cada autor pode ser atribuída como se segue: Paulo Castelo Branco contribuiu com a concepção, obtenção de financiamento e orientação da pesquisa. Bianca Prates, Ellen Feitosa e Paulo Monteiro contribuíram para a conceitualização, coleta de dados, organização e discussão dos resultados. Bianca Prates, Ellen Feitosa e Paulo Monteiro fizeram a redação inicial do artigo e Bianca Prates e Paulo Castelo Branco são os responsáveis pela redação final (revisão e edição).

Os autores agradecem ao CNPq pelo financiamento da pesquisa. Agradecem, ademais, Ana Clara Santos Alves de Oliveira Freitas, Bianca Oliveira Pinheiro, Caio Rudá de Oliveira, Laíse Zanato Velloso, Laryssa Soares Leite e Luiz Humberto Souza Júnior pelo apoio na coleta de dados.

Recebido em: 21/08/2017 $1^{a}$ revisão em: 01/12/2017

Aceito em: 15/04/2018 